\title{
Impact of extreme river events on the coastal ocean
}

\author{
Jasim Imran \\ University of South Carolina - Columbia, South Carolina USA \\ James P.M. Syvitski \\ University of Colorado - Boulder, Colorado USA
}

\begin{abstract}
Small to medium size rivers draining mountainous watersheds are capable of plunging to the ocean floor during large floods. The plunging occurs if the river water becomes heavier than the receiving saline water by transporting an excessive amount of suspended sediment. After plunging to the sea floor, the river water continues to flow as a turbid bottom current. Although infrequent, such events may influence the coastal sediment dispersion and margin architecture in a profound way. One such event is modeled here for the Northern California Margin near the mouth of the Eel River by using a two-dimensional unsteady model. Simulation experiments indicate that the undercurrent has a tendency of flowing towards the adjacent Eel Canyon. However, along-shelf currents may influence the overall development of the underflow by redirection of the flow to other parts of the margin.
\end{abstract}

\section{Introduction}

A river quickly loses its momentum as well as its identity as it enters into a lake or ocean. The reason is the large volume of the water body in which the river discharges. However, if the incoming flow has a density slightly larger than that of the ambient lake or ocean

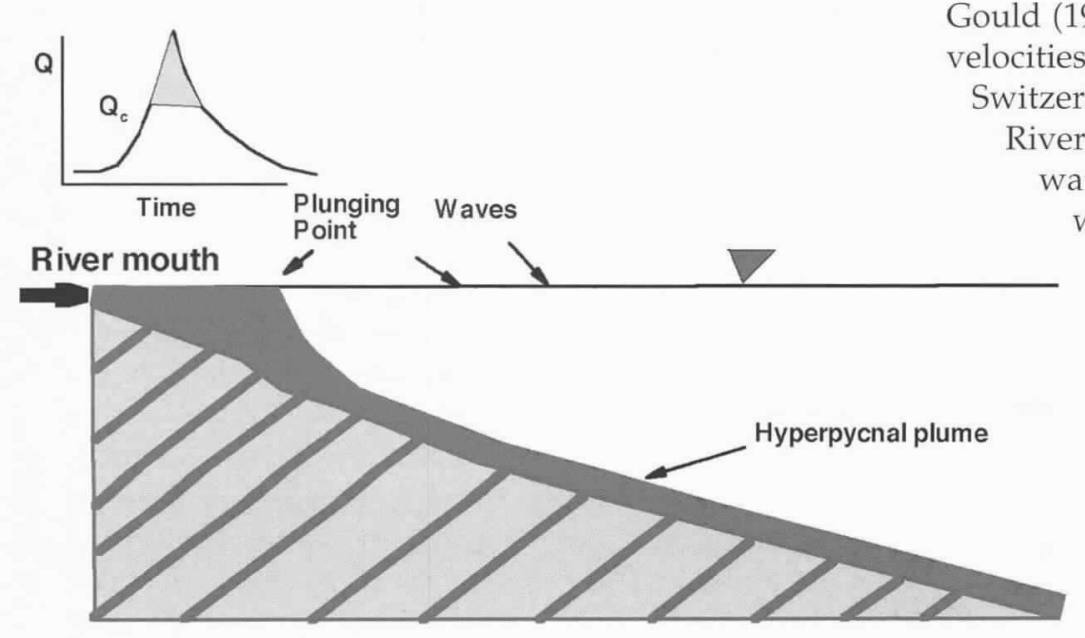

water, the river may plunge to the lake or ocean floor and create a bottom flow commonly known as hyperpycnal plume or turbidity current. The driving force of a turbidity current is obtained from the suspended sediment, which renders the flowing turbid water heavier than the clear water above. Once initiated, a turbidity current can travel a remarkable distance in an otherwise quiescent body of water. If the initial current is strong and erosive it can become even stronger by efficient conversion of kinetic energy to potential energy through the entrainment of sediment from the lake or ocean bed. Swift turbidity currents may be responsible for the formation of many submarine canyons (García, 1992). The initiation of a turbidity current can be caused by several mechanisms such as wave action, subaqueous slumps induced by seismic or other disturbances, mine tailings disposal, or plunging of rivers as a hyperpycnal plume. We are particularly interested in turbidity current generated by plunging of a river's discharge.

Rivers with moderate to small loads of suspended sediment (e.g. $<1 \mathrm{~kg} / \mathrm{m}^{3}$ ) can directly devolve to turbidity currents on the bottom of freshwater lakes. The scientific literature abounds with examples of turbidity currents originating directly from rivers flowing into lacustrine environments, e.g. Forel (18921885), Gould (1952). Lambert (1982) recorded bottom current elocities of more than $100 \mathrm{~cm} / \mathrm{s}$ in Lake Constance, witzerland, generated by the sediment plume of the ver Rhine. Chikita (1989) observed that river water with concentrations greater than $100 \mathrm{~g} / \mathrm{m}^{3}$ would discharge as an underflow in the freshwater Katsurazawa Reservoir, Japan. Weirich

Figure 1. Schematic of plunging processes occurring seaward of a river mouth during large floods. By having a larger density compared to the ocean water, the river is capable of plunging to the ocean floor and continue to flow as a bottom current. The plunging would occur only if discharge is above $Q_{C}$ at which suspended sediment concentration in the river exceeds the critical value of $35 \sim 45 \mathrm{~kg} / \mathrm{m}^{3}$ required for plunging. 
(1984) observed frequent generation of turbidity currents in a small glacial lake in southeastern British Columbia by a stream entering the lake with sediment concentrations as low as $190 \mathrm{~g} / \mathrm{m}^{3}$.

Initiation of a sustained turbidity current from the direct delivery of sediment into the ocean by a river, however, is not common. Seawater has a specific gravity of 1.026 , which poses a strong density barrier to the formation of turbidity currents. The critical concentration of suspended sediment needed to create a hyperpycnal plume in seawater (i.e. direct conversion of river flow to a bottom underflow) is 35 to $45 \mathrm{~kg} / \mathrm{m}^{3}$. There are very few rivers in the world, which discharge into ocean with such a large sediment concentration, even during a flood event (Mulder and Syvitski, 1995).

Despite being a relatively rare hydrologic event, marine hyperpycnal flows associated with large floods remain significant to the seascape evolution. For example, an 11-m thick deposit in the Saguenay Fjord, Eastern Canada, apparently formed from a historical hyperpycnal discharge event (Syvitski and Schafer, 1996; Mulder et al., 1998b). Figure 1 illustrates key processes occurring in a coastal basin during a large flood capable of producing hyperpycnal flow.

\section{Drainage basin to river mouth: factors contributing to marine hyperpycnal events}

Turbidity currents in a marine setting and their deposits commonly known as turbidites are often associated with ignitive transformation of a submarine slide into a density current, e.g. the 1929 Grand Banks event (Hughes-Clarke, 1990) and the 1979 Nice event (Malinverno et al., 1988). On a smaller scale, turbidity currents may occur during the transformation of failed delta foresets or during floods resuspending previously deposited mouth-bar material (Prior et al., 1986; Mulder and Syvitski, 1995). Only recently have scientists started to appreciate hyperpycnal flow as an important mechanism of coastal sedimentation process in modern and geologic times (Normark and Piper, 1991; Mulder and Syvitski, 1995).

Identification of a river's potential for producing hyperpycnal flow in the sea requires the analysis of various hydrologic and oceanic data. Most important for hyperpycnal flow is the suspended sediment concentration at or near the river mouth during a flood. Unfortunately, such data are seldom available for rivers. To overcome this, Mulder and Syvitski (1995) generalized a procedure to estimate peak sediment concentration and flood flow based on the drainage basin area, average river discharge, and average suspended sediment concentration. They proposed that a rating curve between water and sediment discharge, developed from average daily or instantaneous measurement for a specific river, remains valid even during flood stage. This allows calculation of peak suspended sediment concentration from estimated or mea- sured flood discharge of any return period. The peak sediment concentration is then compared with the critical suspended sediment concentration (35 450 $\left.\mathrm{kg} / \mathrm{m}^{3}\right)$. If the estimated peak sediment concentration in the river exceeds the critical concentration determined from the salinity and temperature in the coastal ocean, the river will produce hyperpycnal flow with a given return period,

Mulder and Syvitski (1995) applied a power law (Matthai, 1990) used to estimate historic flood discharge from the drainage basin area of the river, and then determined the hyperpycnal potential for 150 world rivers. They identified 9 "dirty" rivers that can produce hyperpycnal flow on a yearly basis, and 73 moderately dirty rivers that can go hyperpycnal once or more often within 100 years. They further identified 37 moderately clean rivers that can seldom produce hyperpycnal flow, only during 100 to 1000 year megafloods, and 29 clean rivers that can never produce such flow.

Hyperpycnal flows therefore, are exceptional events that occur during floods events in a special category of rivers. None of the 9 dirty rivers are located in the United States. Among the 73 moderately dirty rivers, only nine are located in the United States. Rivers capable of producing bottom flows typically drain small mountainous watershed with easily-erodible sediments, have relatively steep gradient, and have low to moderate annual discharge $(<400 \mathrm{~m} / \mathrm{s})$. With the exception of Huanghe River in China, large rivers are usually not capable of producing underflows at their mouth because of effective sediment entrapment in their expansive coastal floodplains.

\section{Modeling of turbidity current}

Turbidity currents have been the focus of much scientific research over the last several decades because of their role in the evolution of marine sediment strata ranging from continental shelf sands to massive hydrocarbon bearing deep-sea fans (e.g. Bouma, 1962; Normark, 1970, 1978; Mutti and Ricci Lucchi, 1972; Reading and Richards, 1994). Research interest on this topic ranges from field and laboratory observation to numerical modeling at experimental and field scale. Hay (1987), Syvitski and Hein (1991), and Zeng et al. (1991) have all made direct measurement of turbidity current velocity and thickness in fjords. Wright et al. (1986) monitored hyperpycnal flow at the mouth of the Huanghe River in China. The work of Middleton (1967), Fietz and Wood (1967), and Garcío and Parker (1993) are among many experimental studies designed to understand the physics of turbidity currents. Despite their limitation (mostly associated with scaling issues), experimental studies greatly enhanced our understanding of the mechanics of turbidity currents.

Many of the experimental works provided empirical formulae necessary for the closure of governing equations describing the physics of a turbidity currents. The simplest form of numerical modeling of turbidity 


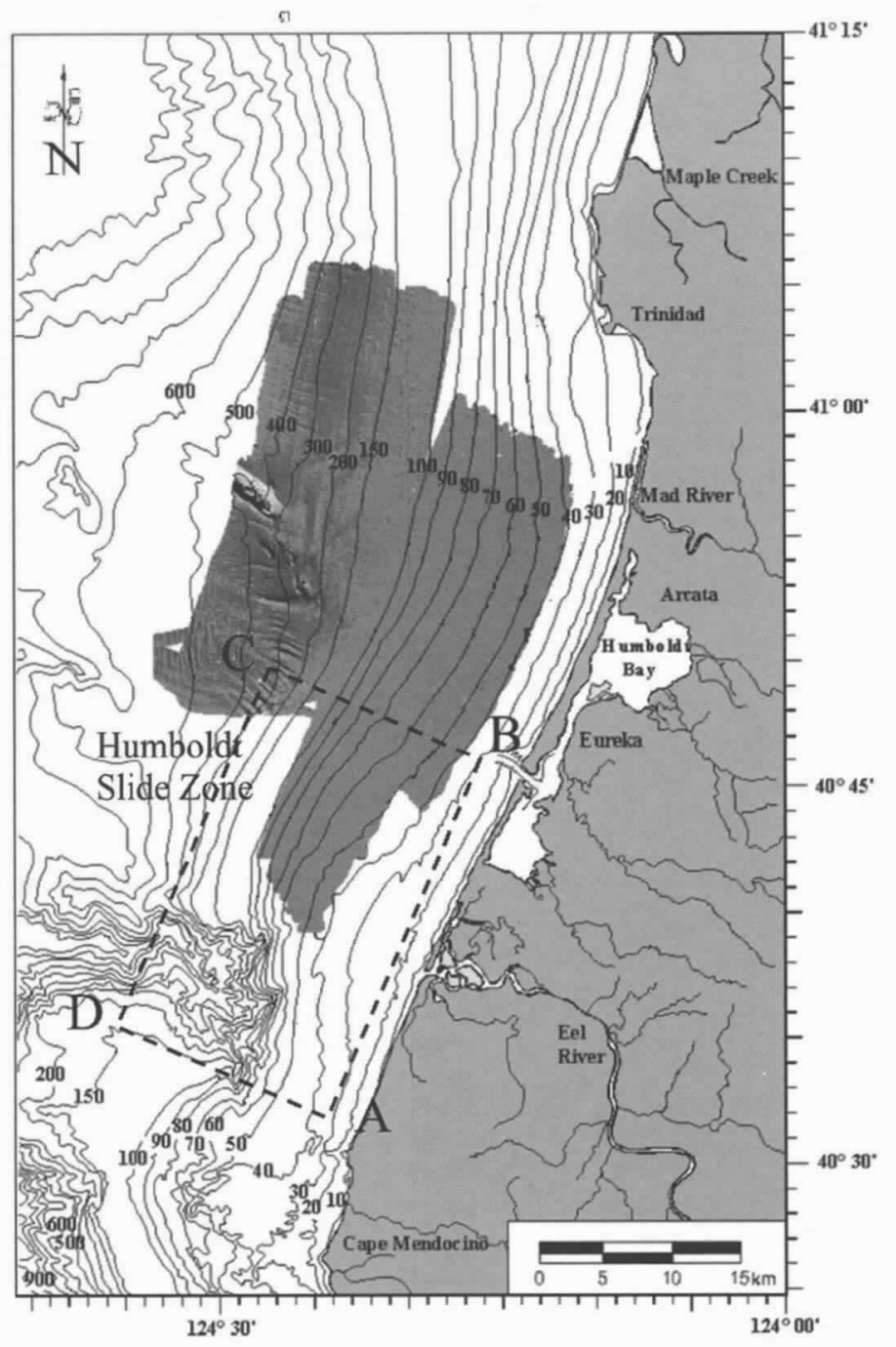

Figure 2. Bathymetry of the Eel Shelf and Margin. The dotted rectangular boundary marked by $A B C D$ represents the computational domain which is shown in three dimension in Figure 4. Superimposed is the published swath imagery of Goff et al. (1999) showing the Humboldt slide region with the enigmatic sediment waves. The distribution and orientation of slope gullies can be also seen near the latitude of $41^{\circ}$ between the $300 \mathrm{~m}$ and $500 \mathrm{~m}$ isobaths.

currents involves balance between gravitational force, flow resistance, and the Coriolis force for a developed flow similar to the normal flow condition in open channel flow (e.g., Komar, 1969; Piper and Savoye, 1993; Mulder et al., 1998b, Hay, 1987). Another popular approach is the solution of the Navier-Stokes equations derived and simplified for turbidity currents using boundary layer approximation (e.g., Fukushima et al., 1985). A detail derivation of equations governing fluid mass and momentum, suspended sediment concentration, and turbulent kinetic energy conservation in a turbidity current can be found in Parker et al. (1986). The generalized equations of turbidity currents can be further reduced to a set of one-dimensional ordinary differential equations by performing vertical integration, and ignoring/averaging the lateral spreading and the temporal variation. This form of the governing equations has gained popularity for modeling of turbidity current and the associated deposit.

Numerical models often consider erosion and deposition by poorly sorted sediment (e.g., García, 1994; Skene et al., 1997). Stacey and Bowen (1988) retained the vertical structure of flow velocity and sediment concentration in their model but ignored the downslope and lateral development. Contrary to the simplification considered in these models, turbidity currents are highly unsteady flow phenomena with significant variation in time and all spatial directions. In particular, hyperpycnal flow generated in the river mouth often spreads into an unconfined area before (if at all) it flows down a submarine canyon or channel at which point the flow may be treated as one dimensional. The front of the current cannot be tracked unless the temporal variation is retained in the model.

Recently Imran et al. (1998) developed an advanced numerical model which solves the governing equations of mass, suspended sediment concentration, and momentum conservation in both downslope and lateral directions using an implicit finite difference scheme. The equations remain vertically integrated. The model also solves the Exner equation of bed sediment continuity to study the evolution of the bed morphology in response to the turbidity current. The model was originally designed to study the inception of channels and levees in submarine fans. This model is adopted here to investigate how hyperpycnal flow events behave on an unconfined shelf and slope. The model of Imran et al. (1998) is modified through coordinate transformation to incorporate the effects of an alongshelf current through coordinate transformation.

\section{Model application}

The STRATAFORM Program of the Office of Naval Research was initiated in 1995 as a coordinated multiinvestigator study of continental margin stratigraphy (Nittrouer and Kravitz, 1996). One of the study areas, located between Cape Mendocino and Trinidad Head (Figure 2) in Northern California, receives fluvial sediment discharge $>10^{7} \mathrm{t} / \mathrm{y}$ from the Eel River (Nittrouer, 1999). The Eel River is a moderately dirty river capable of producing hyperpycnal flow within a 100-year return interval (Mulder and Syvitski, 1995). The river has experienced such floods in 1995 and 1997. After the 1995 flood (Figure 3), only 25\% of the flood sediment discharged by the Eel River has been found on the shelf. The question is where is the remainder of the sediment and by what mechanism has it escaped the shelf? While storm induced current may play a role in resuspending and transporting some of the flood sediment, hyperpycnal discharge may play a dominant role as a sediment transport mechanism during the peak flood flow. If it occurred, a hyperpycnal flow may head towards the adjacent Eel Canyon and transport most of the sediment to the base of the continental slope by feeding through the canyon. A hyperpycnal flow may also be influenced 


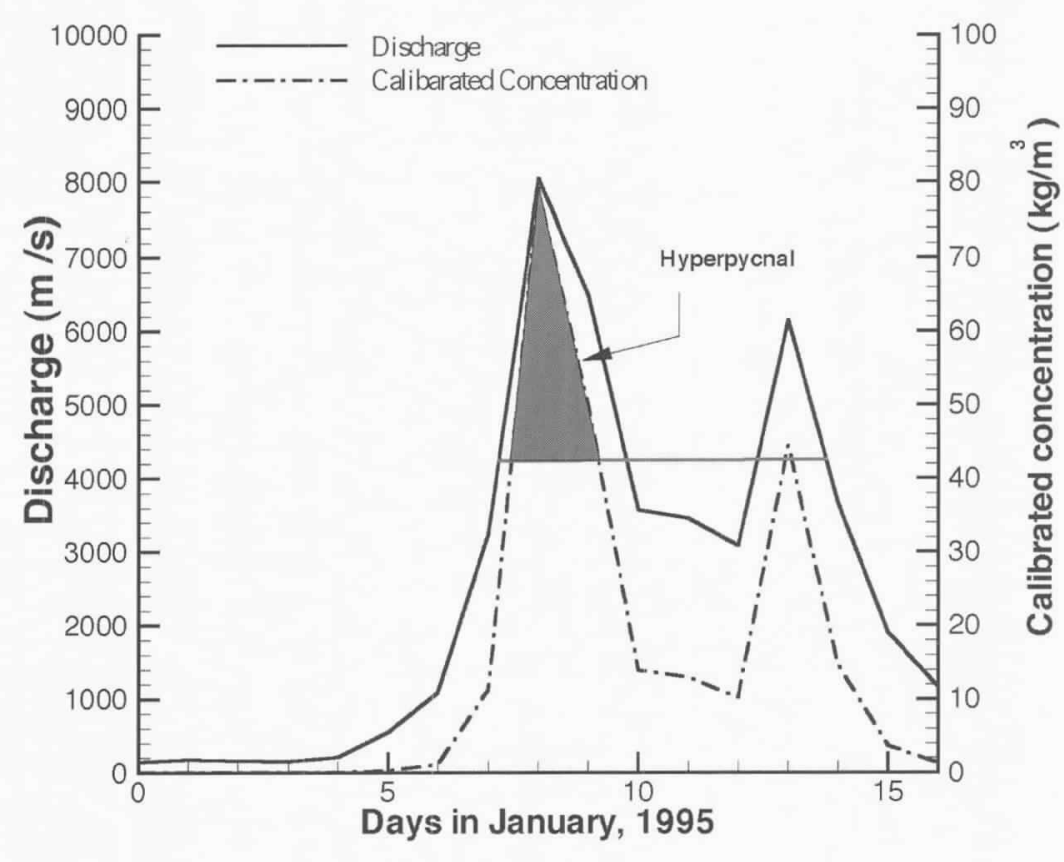

Figure 3. 1995 Eel River flood hydrograph near Scotia. The calibrated concentration hydrograph shows that the density of the river water was sufficient between days 7 and 9 for the river flow to become hyperpycnal. Once plunging occurs, the hyperpycnal flow may continue for days even if the sediment concentration may drop below the critical level for plunging. This is possible due to reduction in salinity near the river mouth by the large volume of fresh water brought by the floodwater.

by the along-shelf currents and be deflected northward away from the canyon.

For illustrative purpose, we describe the 1995 Eel River Flood for its potential for generating hyperpycnal flow. Continuous data for sediment concentration are not available for the duration of the flood. Estimated hydrography for the sediment concentration $\left(Q_{s}=347 \times 10^{-9} Q_{W}{ }^{2.14}\right.$, where $Q_{s}$ is suspended sediment concentration in $\mathrm{kg} / \mathrm{m}^{3}$ and $\mathrm{Q}_{\mathrm{w}}$ is water discharge in $\mathrm{m}^{3} / \mathrm{s}$ ) clearly indicates that the sediment concentration in the Eel River exceeded the critical concentration for plunging over a two-day period (Figure 3). River data from the gaging station located near Scotia are converted into an upstream boundary condition for application in the turbidity current model of Imran et al. (1998). The model requires current thickness, flow velocity, suspended sediment concentration and sediment size distribution at the inflow boundary. Using the rating coefficients of Brown and Ritter (1971), the width of the river is estimated to be $1.5 \mathrm{~km}$ during the flood flow. A computational domain $(22.5 \mathrm{~km}$ long and $37.5 \mathrm{~km}$ wide) is selected as marked in Figure 2.

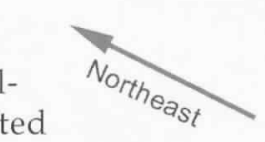
tional domain.
A uniform rectangular grid system $(61 \times 101)$ is used. The computational domain includes the Eel canyon as shown in Figure 4.

For the sake of simplicity it is assumed that the river plunges immediately upon entering into the ocean. The boundary conditions can be summarized as follows: from $A$ to $B$ (Figure 2 and Figure 4) the boundary is treated as a solid wall except for a $1.5 \mathrm{~km}$ opening in the middle at which a current thickness of $4.42 \mathrm{~m}$, velocity of $1.27 \mathrm{~m} / \mathrm{s}$, and a suspended sediment concentration of 0.0188 by volume (with a reduced specific gravity of 1.581) are held constant for the duration of the calculation. Eel River has the following typical grain size distribution of suspended sediment near its confluence with the ocean (Brown and Ritter, 1971) : $20-40 \%$ clay and finer $(<0.004 \mathrm{~mm})$, $40 \%$ silt (0.004-0.062 mm), and $20-40 \%$ sand (> $0.062 \mathrm{~mm}$ ). At the inflow boundary, we have considered the suspended sediment to be composed of $80 \%$ sand $(100 \mu \mathrm{m})$ and $20 \%$ is clay (conservative). The fraction of coarser particles is somewhat exaggerated. This is done intentionally to provide some effects of flocculation in an ad hoc way. The other three sides of the domain i.e., B to C, C to D, and D to $\mathrm{A}$ are considered porous. The flow is allowed to leave the domain when it hits one of these boundaries. The input parameters for the inflow boundary are converted from an average flood discharge of $7000 \mathrm{~m}^{3} / \mathrm{s}$ and associated sediment concentration of $60 \mathrm{~kg} / \mathrm{m}^{3}$ using the empirical formulae devel-

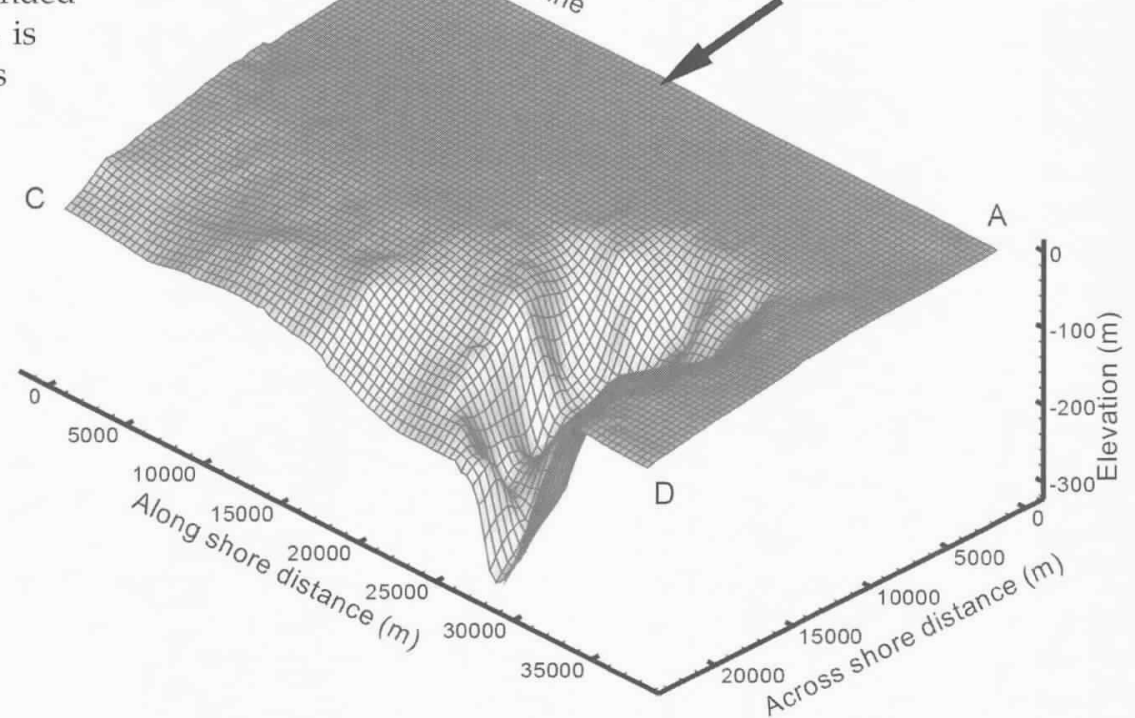

Figure 4. A three-dimensional view of the ocean floor used as the bottom boundary of the computa- 
oped by Akiyama and Stefan (1984). The bottom slope is calculated from the seafloor bathymetry and a constant friction factor (drag coefficient) of 0.003 , a typical value for turbidity currents (Parker et al., 1986).

Based on wind data from NDBC Buoy 46022, Morehead and Syvitski (1999) estimated a range of 0 to $1.4 \mathrm{~m} / \mathrm{s}$ velocity of the along-shelf current during the flood period. The model is applied under different scenarios of along shelf current velocity ranging from 0 to $70 \mathrm{~cm} / \mathrm{s}$ in the Northeast direction. In each case, the model is run for an 8- hour flow period. Velocity vectors plotted in Figure 5a indicates that, if the bottom current is not influenced by the along-shore current, it has a tendency of flowing towards the canyon along a natural gradient from the river mouth. This suggests that the canyon would likely receive direct delivery of water and sediment during geological periods of low sea stand. If not influenced by other forcing factors, the (a) Along shore current velocity, $w=0 \mathrm{~cm} / \mathrm{s}$

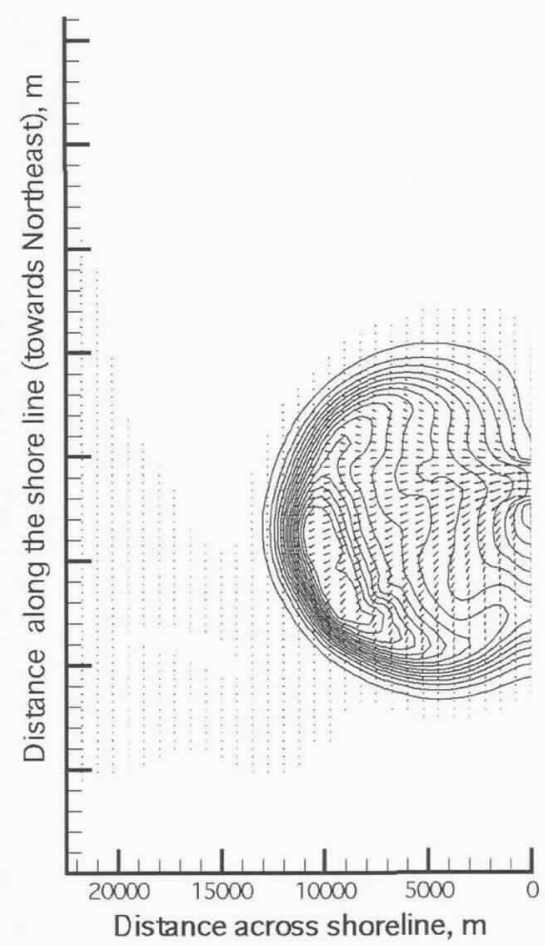

(b)

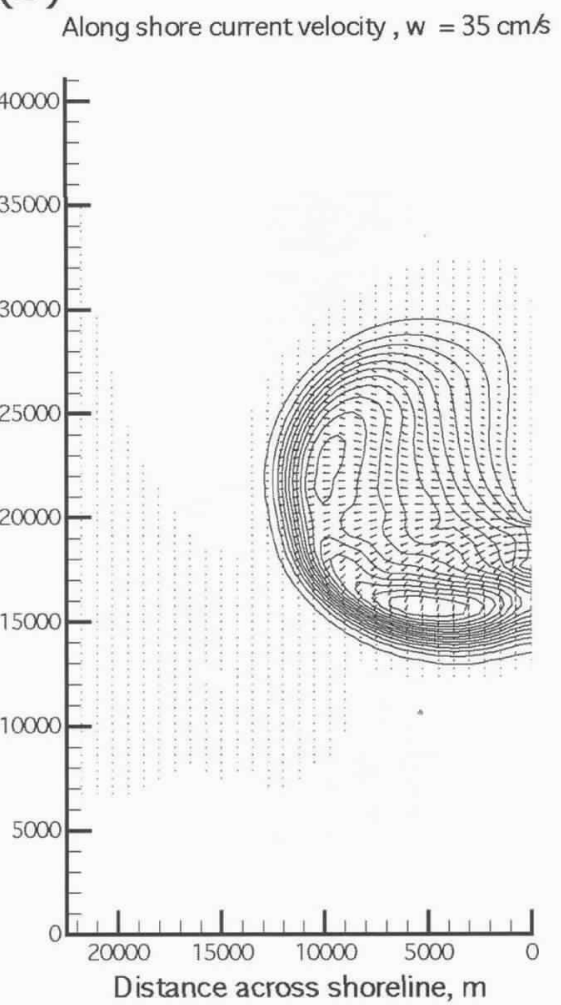

tudes of along-shelf current are plotted in Figure 6. The magnitude and direction of the along-shelf current can significantly influence the shape and direction of the turbid underflow, and therefore the dispersal pattern of sediment delivered by the river during such a flood. For the duration of the simulation, the turbidity current shows very little deposition (not shown in the figure) on its path indicating that the current is strong enough to transport most of the sediment away from the shelf and onto and across the continental slope.

\section{Geological implications of model simulations}

Model results (Figures 5 and 6) explain a number of otherwise puzzling features on the Eel margin. Under conditions of little along shelf current, an Eel hyperpycnal plume would travel to the Eel canyon, where it would flow down the canyon. The STRATAFORM researchers have identified turbidite-like sediment layering in this region, along with areas of seafloor scour (C. Nittrouer, personal comm. 1999). Under conditions of a moderate along shelf current $(35-50 \mathrm{~cm} / \mathrm{s})$, an Eel hyperpycnal plume would spread out and cross the Humboldt slide shelfslope break as a line source (15-20 $\mathrm{km}$ in length) turbidity current and undergo only moderate initial acceleration (possibly explaining an overcompacted zone) before slowing down and depositing its sediment load at the base of the slope (in an area where sediment waves are found: Figure 2; also see Figures 3, 4 , 6 and 7, in Gardner et al., 1999). Episodic hyperpycnal currents combined with ambient storm and surface plume sedimentation could combine over relatively long periods (hundreds to thousands of years) to produce such sediment waves given the influence of repeated floods. The apparent landwardmigrating bed features would be composed of background ambient hemipelagic deposits (surface plume rainout, nepheloid deposiFigure 5. After four hours of flow, velocity vector and flow thickness (a) Under no along-shore current (b) Along-shore current with a velocity of $35 \mathrm{~cm} / \mathrm{s}$ in the Northeast direction. canyon would receive most of the sediment discharge from a turbidity current. Figure $5 \mathrm{~b}$ however, shows that presence of along shelf current with even a modest magnitude in the Northeast direction turns the head of the turbidity current away from the canyon.

Velocity vectors and contours of turbidity current thickness after 8 hours of flow under different magni- tion) and thin bedded turbidites developed from the hyperpycnal events. Under conditions of a strong along-shelf current $(>75 \mathrm{~cm} / \mathrm{s})$, an Eel hyperpycnal plume would spread out farther as it crossed the shelfslope break, to form a $10 \mathrm{~km}$ wide line-source turbidity current where it would re-accelerate before depositing its sediment load. Such hyperpycnal current events 
(a)

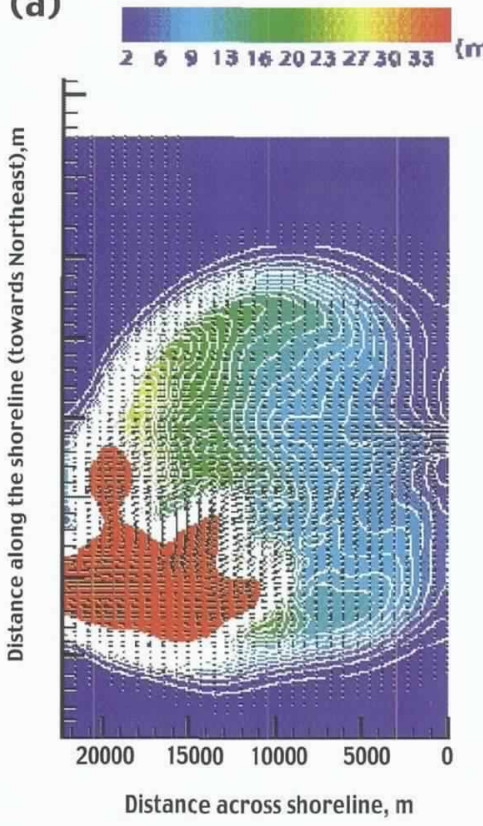

(c)

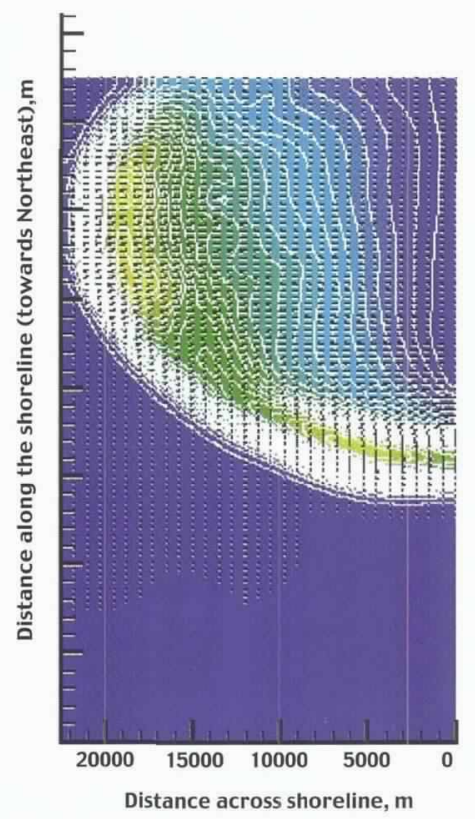

(b)

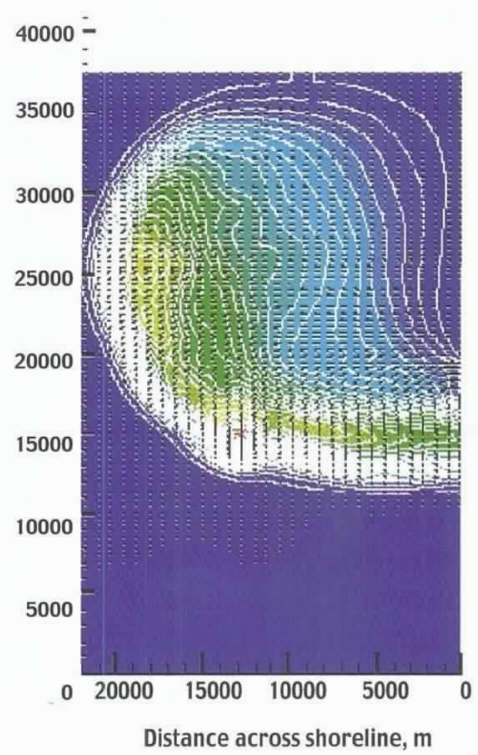

(d)

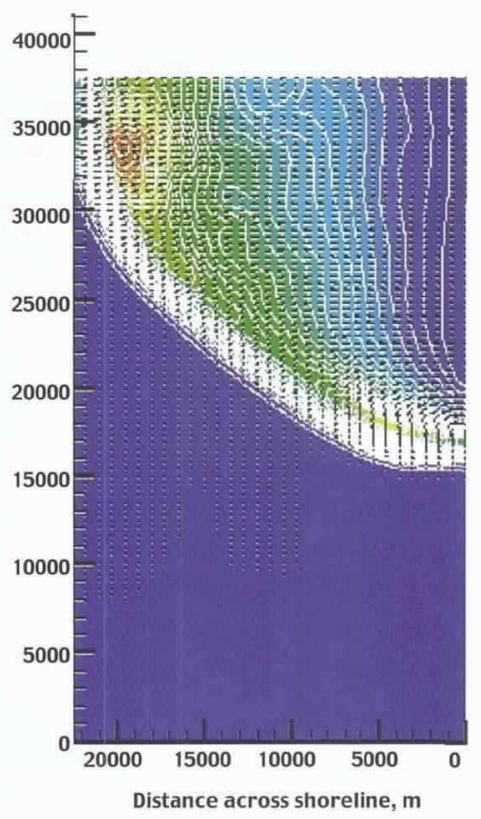

Figure 6. Contour of flow thickness and velocity vector after 8 hours of flow. (a) No alongshore current; (b) Along-shore current magnitude of $35 \mathrm{~cm} / \mathrm{s}$; (c) Along-shore current magnitude of $50 \mathrm{~cm} / \mathrm{s}$ (d) Along-shore current magnitude of $70 \mathrm{~cm} / \mathrm{s}$. The direction of the along-shore velocity is from Cape Mendocino towards Trinidad.

could account for the observed distribution of coarsegrained organic matter (twigs and leaves), and the thin bedded sand layers, observed in cores collected within the slope and plateau (Alexander and Simoneau, 1999). Furthermore, hyperpycnal flows could account for the apparent line source mechanism postulated for conformable slope sedimentation and gully formation (Field et al., 1999).

\section{Conclusion}

Hyperpycnal flow or turbid underflow generated at the ocean floor by plunging of a river during large floods in small to medium size rivers provides an important and efficient sediment transport mechanism and may influence the long term evolution of the adjacent coastal strata. These currents can travel a considerable distance along the shelf, slope, or the canyon and deposit or erode sediment on their way until they lose their identity by encountering very mild slope, or by entraining clean water from the surrounding ambient fluid (saline or fresh water).

A two-dimensional unsteady model of turbidity current is utilized to simulate a hyperpycnal flow which had a strong chance of being generated on the Eel Margin during the peak of the 1995 Eel River Flood. The model inputs are obtained from the river flow data by using an empirical relationship developed for plunging in lakes. The model results confirm that if occurring, such events can carry most of the sediment away from the immediate vicinity of the river mouth. It is also found that the presence of even a small amount of longshore current can turn the head of the current away from its natural tendency of flowing towards the adjacent canyon. It is therefore suggested that in modeling hyperpycnal flow and their deposits, longshore current should be considered.

Finally, some limitations of the model used in this study should be discussed. Even though lateral, downslope, and temporal variations are retained in the model, the vertical variation of flow velocity and sediment concentration have been aggregated by layer-averaging the governing equations. Vertical variation of the longshore current is also ignored. A constant coefficient friction factor is used throughout the computation. Instead of the actual hydrograph, an average value of the discharge and suspended sediment concentration representing the shaded area in Figure 2 is considered in deriving the inflow boundary conditions. The grain size is considered to be consisting of only two size classes. The influence of flocculation is considered only in an ad hoc way. The irregularity along the shoreline is ignored by treating the upstream boundary as a straight line. Many of these limitations can be overcome within the context of the existing model. The result should be viewed as a first look into the dynamics of turbidity currents in the shelf environment. A three-dimensional model of stratified flow that can capture the plunging without resorting to empirical relationships may be desirable for more accurate predictions of the fate of the suspended sediment delivered by the river during historic floods. 


\section{Acknowledgments}

The work presented here was partially supported by grants from the U.S. National Science Foundation (Grant No. 97711431) and the U.S. Office of Naval Research STRATAFORM Program (Grant No. N/N00014-93-1-0300). The insightful comments from the reviewers Neil Driscoll and Thierry Mulder have helped improve the quality of the paper.

\section{REFERENCES}

Akiyama, J. and H.G. Stefan, 1984: Plunging flow into reservoir: Theory. J. Hydraul. Eng., 110(4), 484-499.

Alexander, C.R. and A.M. Simoneau, 1999: Spatial variability in sedimentary processes on the Eel continental slope. Mar. Geol., 154, 243-254.

Brown, W.M. and J.R. Ritter, 1971: Sediment transport and turbidity in the Eel River basin, California. U.S. Geol. Suro. Water-Supply Pap., 1986, 70 pp.

Bouma, A.H, 1962: Sedimentology of Some Flysh Deposits: Graphic Approach to Facies Interpretation. Elsevier, Amsterdam, Netherlands, $168 \mathrm{pp}$.

Chikita, K., 1989: A field study on turbidity currents initiated from spring runoffs. Water Resources Res., 25(2), 257-271.

Field, M.E., J.V. Gardner and D.B. Prior, 1999: Geometry and significance of stacked gullies on the northern California slope. Mar. Geol., 154, 271-286.

Fietz, T.R. and I.R. Wood, 1967: Three dimensional density current. J. Hyd. Div., ASCE, 93(HY6), 1-23.

Forel, F.A., 1885: Les ravins sous-lacustres des fleuves glaciaires. Comptes Rendus, Acad. Sci., Paris, 101, 725728.

Fukushima, Y., G. Parker and H.M. Pantin, 1985: Prediction of ignitive turbidity currents in Scripps submarine canyon. Mar. Geol., 67, 55-81.

Garcia, M., 1992: Turbidity currents. Encycl. of Earth System Sc., 4, 399-407.

García, M., 1994: Depositional turbidity current laden with poorly sorted sediment. I. Hydraul. Engr., 120(11), 1240-1263.

García, M. and G. Parker, 1993: Experiments on the entrainment of the sediment into suspension by a dense bottom current. J. Geophys. Res., 98(c3), 47934807.

Gardner, J.V., D.B. Prior and M.E. Field, 1999: Humboldt Slide - a large shear-dominated retrogressive slope failure. Mar. Geol., 154, 323-338.

Goff, J.A., D.L. Orange, L.A. Mayer and J.A. HughesClarke, 1999: Detailed investigation of continental shelf morphology using a high-resolution swath sonar survey: the Eel margin, northern California. Mar. Geol., 154, 255-269.

Gould, H.R., 1952: Some quantitative aspects of Lake Mead turbidity currents. Soc. Econ. Palcont. Mincral. Special Pub., 2, 34-52.

Hay, A.E., 1987: Turbidity currents and submarine channel formation in Rupert Inlet, British Columbia, 1.
Surge observations. J. Geopllys. Res., 92(c3), 2875-2881.

Hughes-Clarke, J. E., 1990: Late-stage slope failure in wake of the 1929 Grand banks earthquake. GeoMarine Let., 10, 69-79.

Imran, J., G. Parker and N. Katopodes, 1998: A numerical model of channel inception on submarine fans. J. Geophys. Res., 103(C1), 1219-1238.

Komar, P.D., 1969: The channelized flow of turbidity currents with application to Monterey deep-sea fan channel. J. Geoplys. Res., 74, 4544-4557.

Lambert, A.M., 1982: Trubestrome des Rheins am Grund des Bodensees. Sonderdruk ausTurbidity currents from the Rhine River on the bottom of Lake Constance. Wasserwirtschaft, 72(4), 1-4..

Malinverno, A., W.B.F. Rayan, G. Auffret and G. Pautot, 1988: Sonar images of recent failure events on the continental margin of Nice, France. Geol. Soc. Amer. Special Paper, 229, 59-75.

Matthai, H.F., 1990: Floods. In: The Geology of North America: Vol. O-1, Surface Water Hydrology: Boulder, Co. M.G. Wolman and H.C. Riggs, eds., Geological Society of America, 97-120.

Middleton, G.V., 1967: Experiments on density and turbidity currents, III: Deposition of sediment. Can. J. Earth Sc., 4, 297-307.

Morehead, M. and J.P.M. Syvitski, 1999: River-plume sedimentation modeling for sequence stratigraphy: application to the Eel margin, Northern California. Mar. Geol., 154, 29-41.

Mulder, T. and J.P.M. Syvitski, 1995: Turbidity currents generated at river mouths during exceptional discharges to the world oceans. J. Geology, 103, 285-299.

Mulder, T., B. Savoye, D.J.W. Piper and J.P.M. Syvitski, 1998a: The Var submarine sedimentary system: understanding Holocene sediment delivery processes and their importance to the geologic record. In: Geological Processes On Continental Margins: Sedimentation, MassWasting and Stability. M.S. Stoker, D. Evans and A. Cramp, eds., Geological Society, London, 129, 145-166.

Mulder, T., J.P.M. Syvitski and K.I. Skene, 1998b: Modeling of erosion and deposition by turbidity currents generated at river mouths. J. Sed. Res., 68(1), 124-137.

Mutti, E. and F. Ricci Lucchi, 1972: Le torbiditi Deil' Appenino Settentrionale- introduzione all'analisi di Facies. Soc. Geol. Ital. Mem., 11, 161-199.

Nittrouer, C. A. and J.H. Kravitz, 1996: STRATAFORM: A program to study the creation and interpretation of sedimentary strata on continental margins. Oceanography 9(3), 146-152.

Nittrouer, C.A., 1999: STRATAFORM: overview of its design and synthesis of its results. Mar. Geol., 154, 312.

Normark, W. R., 1970: Growth Patterns of Deep Sea fans. Bull. Am. Ass. Pet. Geol., 54, 2170-2195.

Normark, W. R. and D.J.W. Piper, 1991: Initiation processes and flow evolution of turbidity currents: 
implications for the depositional record. SEPM Special Pub., 46, 207-230.

Parker, G., Y. Fukushima and H.M. Pantin, 1986: Selfaccelerating turbidity currents. J. Fluid Mech., 171, 145-181.

Piper, D.J.W. and B. Savoye, 1993: Processes of late Quaternary turbidity current flow on the Var DeepSea Fan, North-West Mediterranean Sea. Sedimentology, 40, 557-582.

Prior, D.B., B.D. Bornhold and M.W. Johns, 1986: Active sand transport along a fjord bottom channel, Bute Inlet, British Columbia. Geology, 14, 581-584.

Reading, H.G. and M. Richards, 1994: Turbidity Systems in Deep-water basin margins Classified by Grain size and Feeder System. AAPG Bulletin, 78(5), 792-822.

Skene, K.I., T. Mulder and J.P.M. Syvitski, 1997: INFLO1: A model predicting the behaviour of turbidity currents generated at river mouths. Computers and Geosciences, 23(9), 975-991.

Stacey, M.W. and A.J. Bowen, 1988: The vertical structure of density and turbidity currents: Theory and observations. J. Geophys. Res., 93(C4), 3528-3542.
Syvitski, J.P.M. and C.T. Schafer, 1996: Evidence for an earthquake-triggered basin collapse in Saguenay Fjord. Canada. Sed. Geol., 104, 127-153.

Syvitski, J.P.M. and F.J. Hein, 1991: Sedimentology of an arctic basin: Itirbilung Fiord, Baffin Island, Canada. Geological Survey of Canada, Professional Paper 9111, $67 \mathrm{pp}$.

Weirich, F.H., 1984: Turbidity currents: monitoring their occurence and movement with a three-dimensional sensor network. Science, 224, 384-387.

Wright, L.D., Z.-S. Yang, B.D. Bornhold, G.H. Keller, D.B. Prior and W.J. Wiseman Jr., 1986: Hyperpycnal flumes and plume fronts over the Huanghe (yellow River) Delta Front. Geo-Marine Letters, 6, 97-105.

Zeng, J., D.R. Lowe, D.B. Prior, W.J. Wiseman Jr. and B.D. Bornhold, 1991: Flow properties of turbidity currents in Bute Inlet, British Columbia. Sedimentology, 38(6), 975-996.

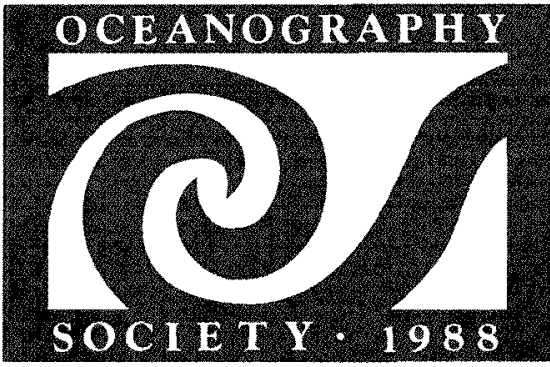

